Some degree of sepsis Sepsis. surface is less able to resist either a fresh invasion or the growth of organisms unscathed by the heat. Powerful antiseptics cannot be applied, nor can weak ones be frequently used. In many cases the attempt to apply a theory may do more harm than good; hence digressions from established authority should be very carefully introduced. I know of no better antiseptic for a burned surface than normal sheep's or horse's serum; the cost is its only drawback. Pneumonia, which accounts for many of the deaths after burns, is probably a manifestation of sepsis, and is produced by a septic embolism.

Duodenal Vlcer.

This is, in my experience, incidentally rarer among the burned than among those not so affected. I have never seen one case in patients suffering from burns. It is more the figment of the imagination of the student going in for an examination.

\section{Surgical Intervention.}

In many cases we do not apply the principles of surgery early enough. At first burned patients are unable to sustain further inroad into their vitality, and later on it is sometimes forgotten that surgery may improve the outlook, both as regards immediate morbidity and ultimate appearance. Where a limb has been almost denuded of skin carly amputation is indicated. Short of this it will be found in many cases-and this is the experience of most of us-that an ulcer produced by surgery is much less severe than one resulting from $\dot{a}$ burn. It is the uncertainty of our judgement regarding the vitality of any section of burned surface which makes us hesitate to resort to extensive excisions. It is often surprising how many islets of epithelium appear among the granulations after the slough of what we considered to be the entire thickness of skin has separated. Even though we may finally have larger areas to epithelialize than would have formed without excision we certainly lessen suffering very materially. I think the tendency hitherto has been conservative. Simultaneously with the excision provision should be made for grafting. Large ulcers are to be treated upon general lines; the longer they remain the greater will be the tendency for contractures to occur. On the other hand, acquiescing in the production of a contracture may result in a rapid obliteration of the ulcer, yet such a contracture should not be allowed to develop, but the ulcer should be healed by other means.

\section{Grafting}

Successful grafting requires careful preparation of the field; indeed, until the septic process has ended grafting should not be undertaken if the Thiersch or Wolff method be adopted. Many years ago I introduced a method of grafting to which the name of "tunnel" grafting was given; it can be applied at an earlier stage than any cther, and has a high percentage of successes. Narrow grafts are embedded under the surface and their locality marked by laying alongside them suture threads. After allowing for their taking root, which occurs in about ten days, the covering surface is removed so as to expose the grafts completely. On account of the close resemblance of the granulation tissue developed to sarcomatous tissue in its destructive effects a thin epithelial covering is almost certain of being destroyed from time to time. This feature of constantly recurring ulceration must be familiar to all; hence a solid covering is essential if healing is to be permanent. It is interesting to note that if embedded grafts are left for any length of time under or in the granulations they entirely disappear. This is a usual phenomenon, otherwise operation implantation grafts would be commoner.

As an aid to the spread of epithelium scarlet-red applied in an ointment is a very decided stimulant. Where serious grafting is required the pedicled graft is best; it is often noticeable that sepsis tends, when these grafts are freed, to light up the processes of ulceration. This development sometimes is the cause of failure in grafting for the relief of contracture even in cases long since healed. It would seem that cicatricial tissue is capable of retaining, encysted within its meshes, infection in an active state. The development of keloid is one evidence of such a power.

In considering burns generally we nearly always have in our minds the effects of heat; yet cold, chemicals, ultiaviolet rays in sunlight direct or reflected from snow, or those produced electrically, induce similar disturbances. Another form of burn, fortunately now less common, is that produced by radium and $x$ rars. Burns so caused show great lesistance to healing, and their tendency to become malignant is well recognized. Occasionally when an ordinary burn has been allowed to pass into a chronic ulcer malignancy may become engrafted.

\section{Discussion.}

Mr. W. C. Wilson (Edinburgh) gare his experiences with tannic acid in the treatment of 37 cases of burns in children. He said that at the stage of initial shock tannic acid was beneficial in that it promoted a rapid and complete analgresia. In the stage of acute toxaemia the main indication was to prevent absorption of the toxin; in this respect the action of tannic acid was striking and valuable, for by coagulating the tissues at the burnt area it prevented absorption of toxin into the blood stream. In the stage of septic toxaemia tannic acid, by providing a firm, dry covering to the wound, minimized the incidence of sepsis; it also protected the growing epithelium and promoted rapid healing. Primary shock was treated in the usual way--a small dose of morphine being given if necossary. No general anaesthesia was employed. The burnt areas were cleansed rapidly with ether. A fresh!y prepared solution of $2 \frac{1}{2}$ per cent. of tannic acid in warm sterile water was sprayed over the burnt areas at intervals of an hour, and the application was dried by electrical heat. This was continued until a brownish-black coagulum formed (eight to twelve times). The bed-clothes "were cradled and the parts exposed to the air during this time and until the coagulum was removed. While spraying the face, the eves, ears, and nostrils must be protected. Slides were shown to illustrate the effect of treatment on mortality, the prevention of acute toxaemia, and the improvement in prognosis thus obtained.

Mr. Sreward (London) agreed that tamnic acid gave excellent results. He proferred to make a careful toilet under anaesthesia at the beginning of treatment.

Mr. R. M. Manwaring-White (Northwich) said that the three essentials of relief of pain, treatment of shock, and prevention of sepsis were obtained by using the pommade of Reclus, which contained phenazone, salol, boric acid, iodoform, phenol, mercury perchloride, and raseline.

\section{A CASE OF ABNORMAL FAT METABOLISM. \\ BY}

JAMES A. TORRENS, M.D., F.R.C.P., PHYSICIAN, ST. GEORGE'S HOSPITAL

H. Gatisborough, M.B., M.R.C.P., AsSISTANT PHYSICIAN, ST. GzORGE's hOSPITAL; AYD

J. A. GARDNER, M.A., READER IN PHYSIOUOGICAL CHEMISTRY, UNIVERSITY OF LONDON.

THe clinical symptoms in the following unusual case suggested some defect in fat metabolism, and in the hope of ascertaining its nature a thorough investigation was made; the results, though they did not explain the mystery, seem worthy of record.

A girl, aged 13, was sent to hospital because her mother had A girl, aged 13, loss of weight for two years; she had not noticed progressive loss of weight for two years; she had not
seemed ill; her appetite was uniformly good; her bowels were open naturally, and she was quite ordinarily energetic, though during the last the child various tonics, and had persistently tried to had given the child various tonics, and had oil; these extra fatty feed her up with cream, milk, and cod-liver on, these extra fatty foods were taken readily, and hation had not started. There had been no previous illness of note. 
When admitted, on December 15th, 1926, she was a small, bright fresh complexioned alert child weighing $47 \frac{1}{2} \mathrm{lb}$. (the normal weight for a girl of 13 is $87 \mathrm{lb}$.), lips and skin rather dry, tongue clean and moist, teeth good. The heart, lungs, abdomen, tongue clean and moist, teeth good. The heart, lungs, abdomen, and central nervous system were all normal. With the exception
of the face, which appeared normal, there was throughout the entire body an almost complete absence of all subcutaneous fat the muscles standing out under the skin as in wasting disease. This was more noticeable in the arms, thorax, and abdomen than in the legs. The muscular power was unimpaired. The urine was normal, as were the stools, both to the naked eye and to microscopical and cultural examination. Clinically it seemed probable that there was some defect in fat metabolism and it was decided to try a diet in which the fat content should be materially reduced; the effect was dramatic, as is shown on the accompanying graph.

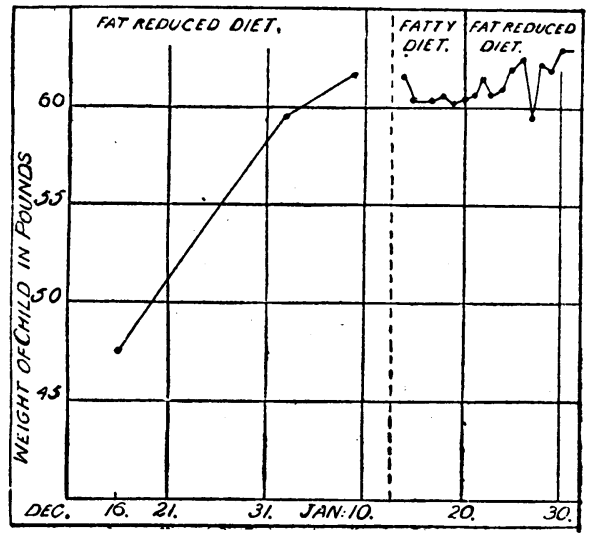

The sudden temporary drop in weight on January $27 \mathrm{th}$ was due to polyuria following a sugar tolerance test.

From a study of the child's weight in relation to the diet it soon became clear that on an ordinary mixed diet the weight slowly but steadily decreased, but that when the fat intake was restricted (by no means completely) there was a rapid gain in weight, amounting in one period of twenty-five days to $14 \mathrm{lb}, 6 \mathrm{oz}$ and in a later period of ten days to $2 \mathrm{lb} .3 \mathrm{oz}$. From the clinical and in a later period of ten days to $2 \mathrm{lb}$. $3 \mathrm{oz}$. From the clinical these facts, so certain investigations were made to see if any light could be thrown on the cause of the abnormal metabolism. The following figures were obtained :

December 22nd (fat-restricted diet) : Blood sugar 0.0798 (ShafferHartmann). Plasma cholesterol : free, 0.04904 per cent.; ester, 0.07224 per cent.; total, 0.1213 per cent. Percentage of total as ester, 59.8. Total solids of plasma, 9.338 per cent.

January 26th (fat-restricted diet): Glucose (25 grams) was January 26th (fat-restricted diet) : Glucose (25 grams) was
administered and the sugar tolerance test performed. This showed : Blood sugar, 0.104; after half an hour, 0.126 ; after one hour, 0.155; aiter one and a half hours, 0.150 ; after two hours, 0.102 ; after two and a half hours, 0.093 .

January 27th. Urine analysis: Volume in twenty-four hours, 1,095 c.cm.; specific gravity 1016.7; total nitrogen, 0.84 per cent.; iree ammonia, 0.032 per cent.; urea, 1.325 per cent. Sulphir excretion was as follows:

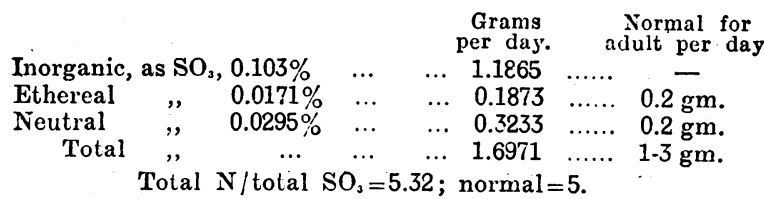

The analysis of the urine was made on the day following the sugar tolerance test, the twenty-four-hour volume being as stated. The average daily volume was about $600 \mathrm{c.cm}$.

The respiratory quotient was also determined during the period of restricted diet, at intervals after a meal consisting of $4 \mathrm{oz}$. of meat, $2 \mathrm{oz}$. of greens, $3 \mathrm{oz}$. of potatoes, $1 / 2 \mathrm{oz}$. of bread, $4 \mathrm{oz}$. of tapioca pudding, and a glass of water. The respiratory was determined on ten-minutes samples of expired air, using a Douglas bag. The patient was quiet throughout the experiment and breathing normally. The meal was taken at 11.45 a.m. At 2 p.m. the respiratory quotient was 0.87 ; at 2.30 p.m. it was 0.87 ; and at 3 p.m. it was 0.86 .

Fat balance experiments were also made over two periods of three days each. In the first period (December 17th to 19th in clusive) the diet was restricted as regards fats by omission of butter and eggs and by using lean meat. In the second perio (January 17th to 19th inclusive) the patient had an ordinary including $2 \mathrm{oz}$ of butter $4 \mathrm{oz}$ of milk milk pudding a die egg. On gay. On days previously and was carefully measured. Duplicate diets wer collected throughout and also the faeces during the seventy-twoour periods.

The whole of the food with the exception of the fluids and the butter, which were separately estimated, was dried and ground in a mill and a portion of the thoroughly mixed meals so obtained was analysed. The sterol balance was also determined oburing the second period, on the non-restricted diet, a nitroden buring was also ascertained by analysis of the faeces and urine. The resulls wcre as follows.
Fat-restricted Diet (December 17th to 19th). Fatty Diet (January 1.th to 19th).

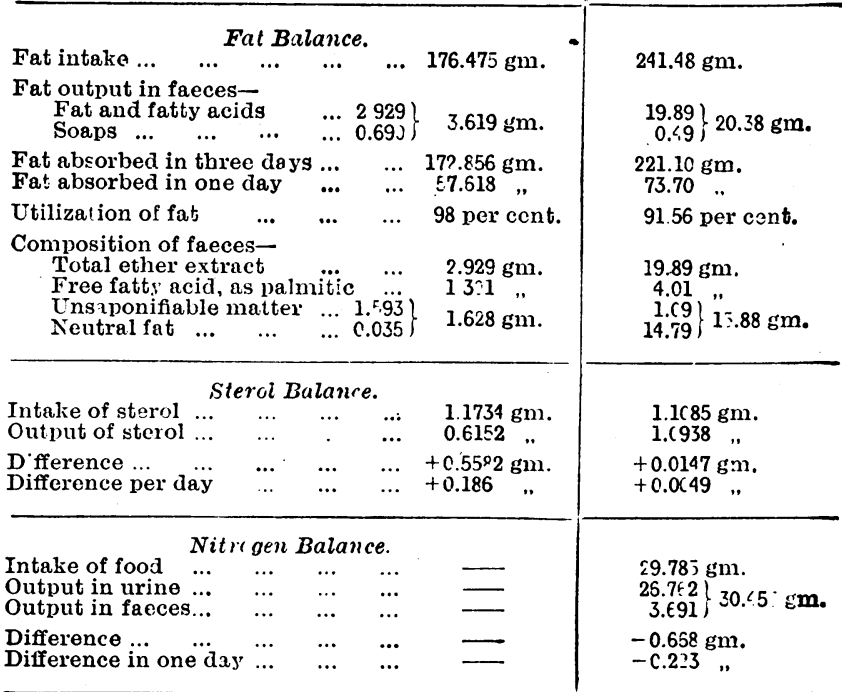

Comment.

These investigations on the whole yielded normal figures. The blood sugar, total solids, and cholesterol of plasma were normal, as also were the respiratory quotients. Ono noteworthy figure was the high value for neutral sulphur in the urine, which is generally considered an expression of the endogenous protein metabolism.

The nitrogen balance during the unrestricted diet period showed an-insignificant increase of output over intake, corresponding in direction with a slight loss in weight during that period.

The fat balances were interesting insomuch as they showed the completeness of the fat splitting and the fat absorption from the alimentary canal. The sterol balances. show a remarkable arreement with the change of the patient's weight in the two experimental periods. During the first period the excess of intake over the output was 0.186 gram per day. The gain in the patient's weight at this time averaged 307 grams a day, and if we take an average figure of 0.06 per cent. for the sterol content of body tissues this would correspond to a utilization of 0.184 gram. During the second period, when there was a very slight loss of weight, the sterol balance was almost exact, the actual figure for the difference of intake and output being within the limits of experimental error.

It is very diflicult to draw any conclusions as to the nature of the anomalous metabolism. Clearly the error was not one of intestiual malabsorption of fat. The clinical improvement was dependent on only a moderate restriction of fat intake from 80 grams a day to 59 grams. The respiratory quotient, determined after a mixed meal, and the evidence relating to the carbohydrate metabolisn threw no light on the mystery. In the use of the two diets, in one case approximately 58 grams of fat was absorbed a day and in the other 74 grams. This latter cortainly represents an urnecessarily high fat intake, but does not correspond to such marked increase of the fat to carbohydrate ratio as to suggest any failure in the efficient metabolism of fat from this cause. Acetone bodies wero never found in the urine, and the glucose toleranco was quite normal.

It is to be remembered that when the observations were commenced the child was markedly under weight and the restriction in the fat intake allowed her to become more nearly normal. At a later date the ingestion of a fatty diet again caused loss of weight and appeared to act as metabolic poison. This excess of fat was well absorbed, and throughout the experiments thero was no failure of alimentary function. From our evidence it seems impossible to explain why a high fat intake should interfere with the normal deposition and storage of fat in the body tissues. 